SUPPORTING INFORMATION

\title{
Iodine Capture Using Zr-based Metal-Organic Frameworks (Zr-MOFs): Adsorption Performance and Mechanism
}

Peng Chen, ${ }^{a, *}$ Xihong He, ${ }^{b, *}$ Maobin Pang, ${ }^{a}$ Xiuting Dong, ${ }^{a}$ Song Zhao, ${ }^{a}$ Wen Zhang ${ }^{a *}$

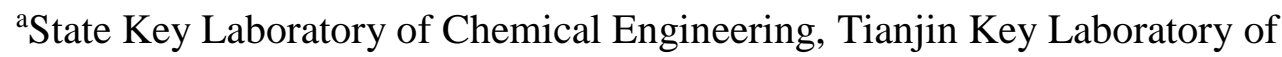

Membrane Science \& Desalination Technology, and School of Chemical Engineering and Technology, Tianjin University, Tianjin 300350, China

${ }^{\mathrm{b}}$ School of Metallurgical Engineering, Xi'an University of Architecture and Technology, Xi'an, 710055, China

*To whom correspondence should be addressed. E-mail: zhang_wen@tju.edu.cn.

these authors contributed equally.

Number of Tables: 2; Number of Figures: 21. 


\section{$1{ }^{1} \mathrm{H}$ NMR spectra of digested MOF-808 after activation}

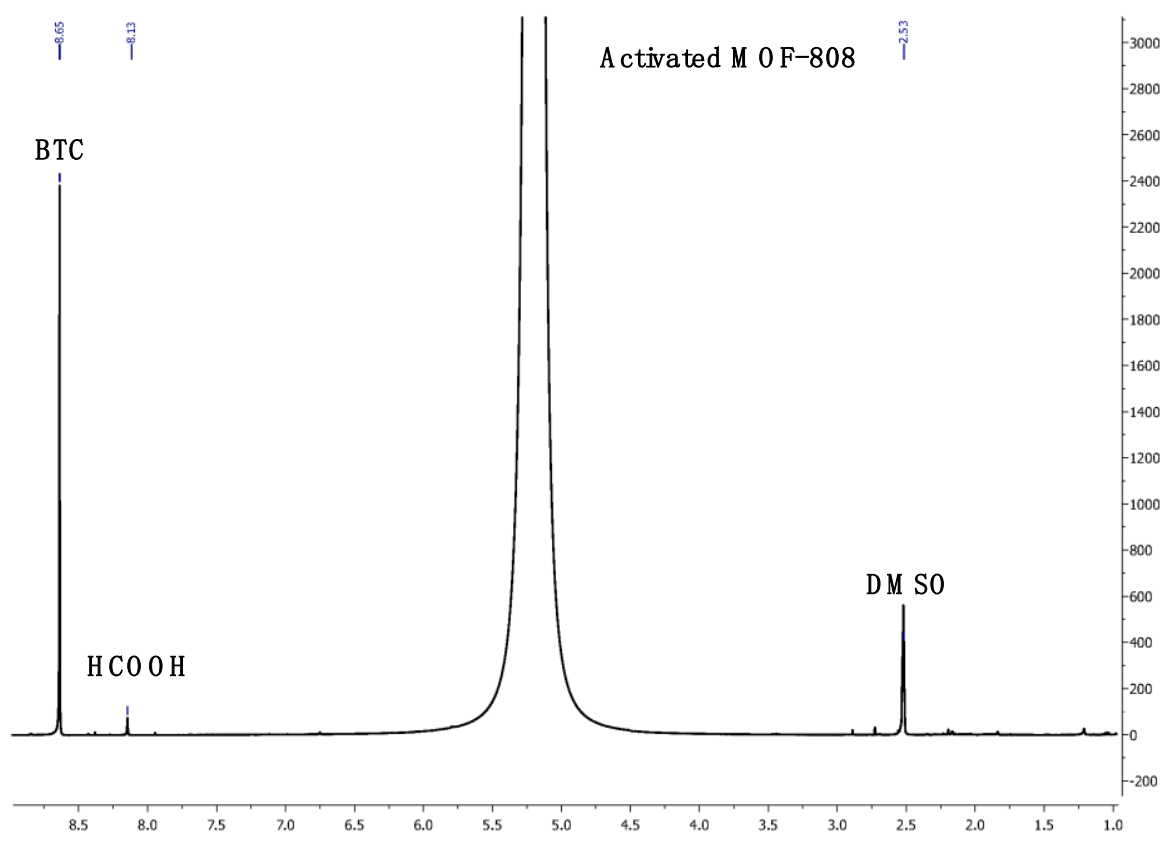

Figure S1. ${ }^{1} \mathrm{H}$ NMR spectra of digested MOF-808 after activation (HF/ $d_{6}$-DMSO).

2 The re-adsorption ratio in recyclability tests under humid conditions (18\% $\mathbf{R H})$

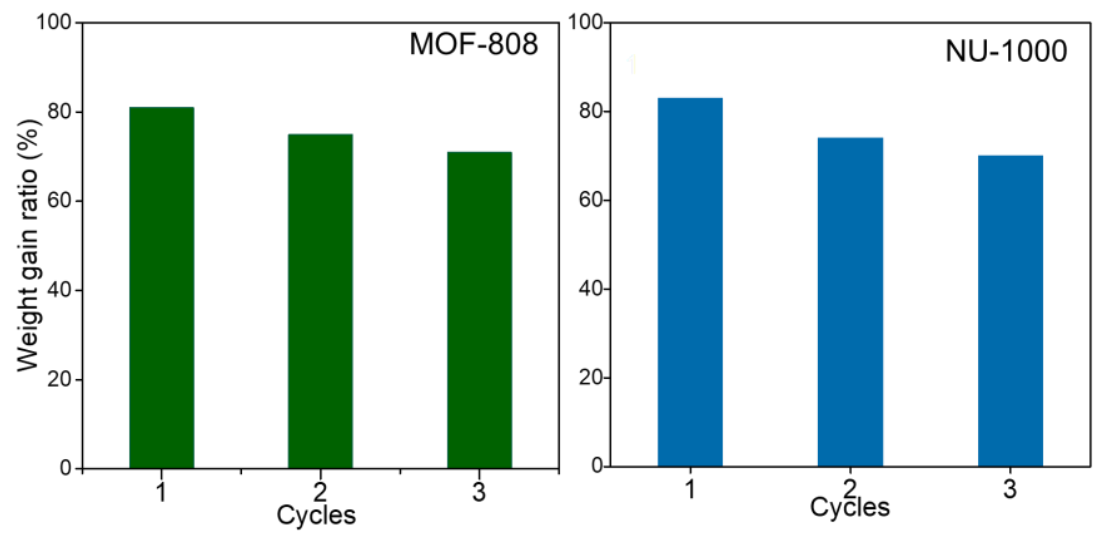

Figure S2. The re-adsorption ratio in the in the recyclability tests under humid conditions $(18 \% \mathrm{RH})$, calculated via dividing the weight gain in each cycle by the amount of weight gain in the first time. 
3 Incorporating pyridine/imidazole ligands into the $\mathrm{Zr}$ clusters of MOF-808/NU-

\section{0 via ligand exchange}

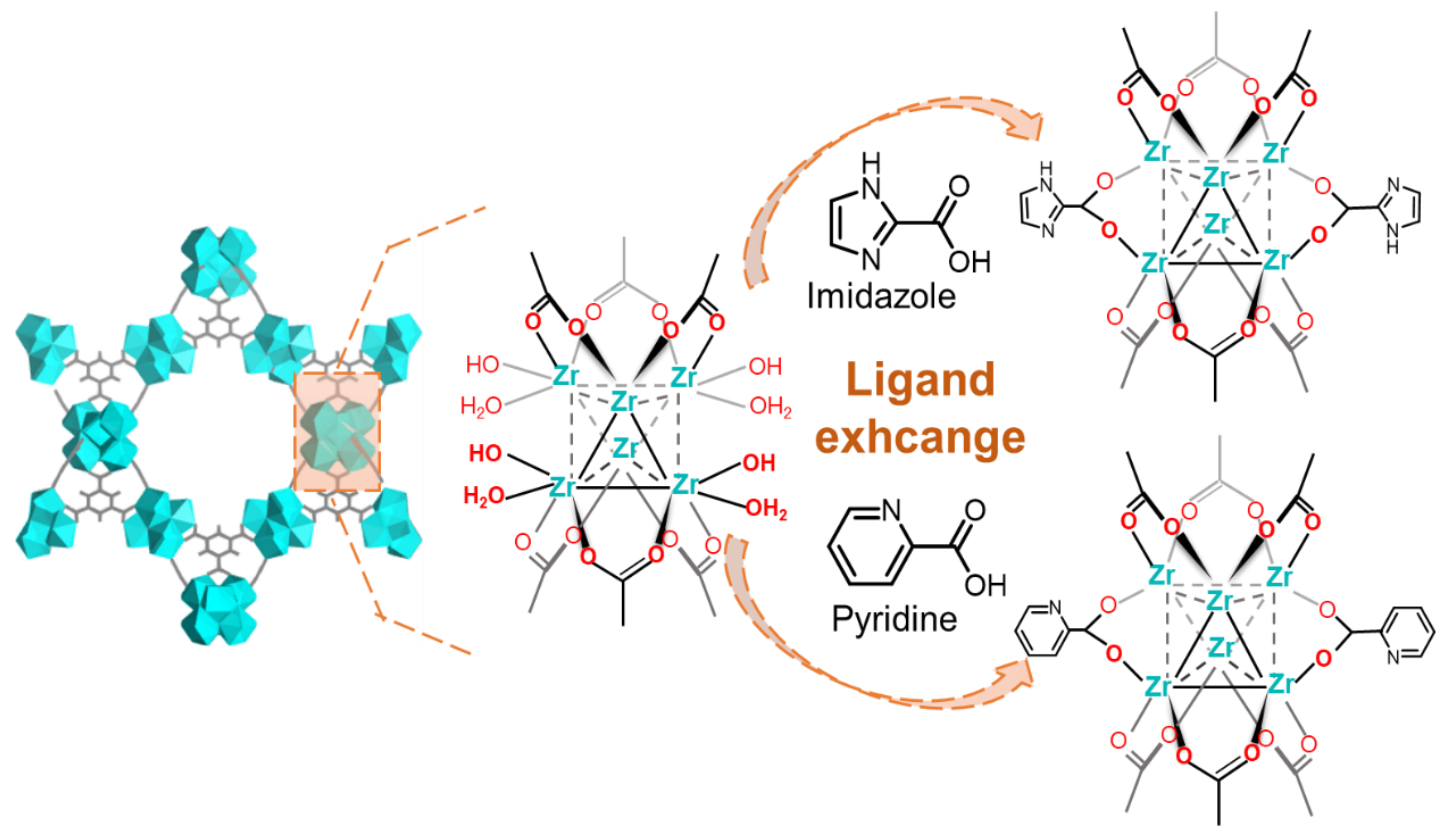

Figure S3. The scheme of incorporating pyridine/imidazole ligands into the $\mathrm{Zr}$ clusters via ligand exchange.

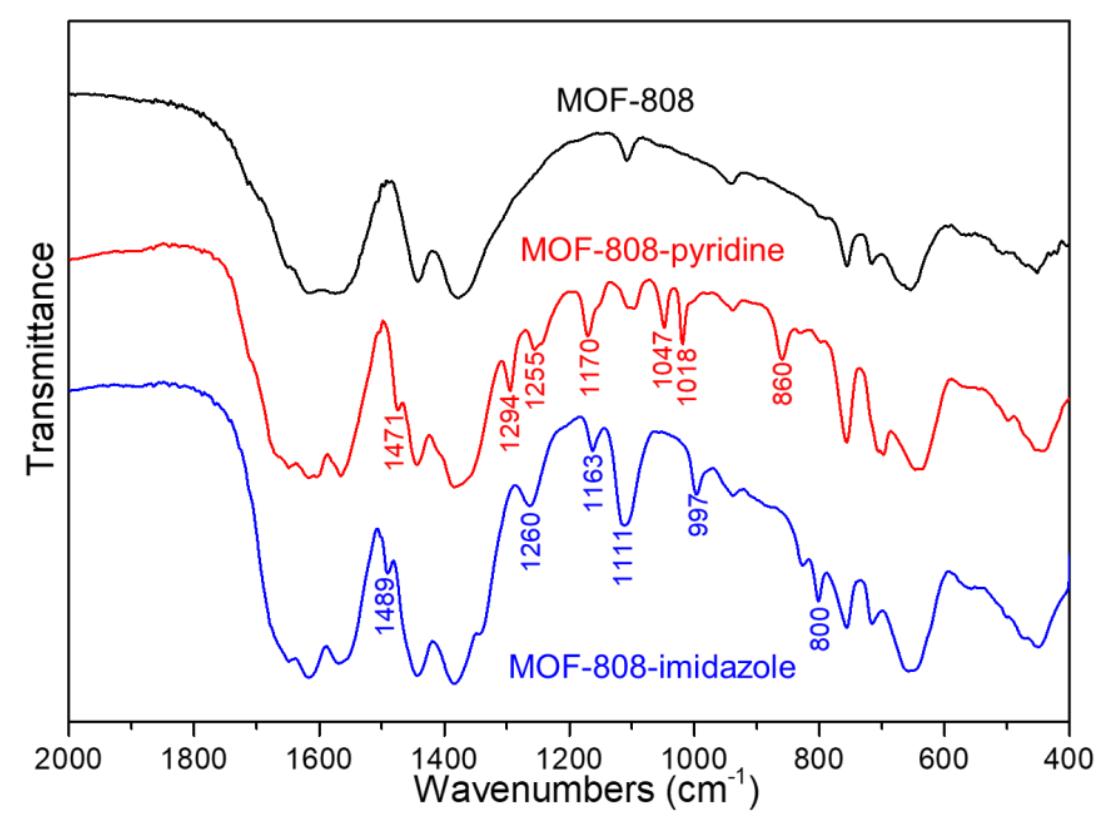

Figure S4. FTIR spectra of MOF-808, MOF-808-pyridine and MOF-808-imidazole. 


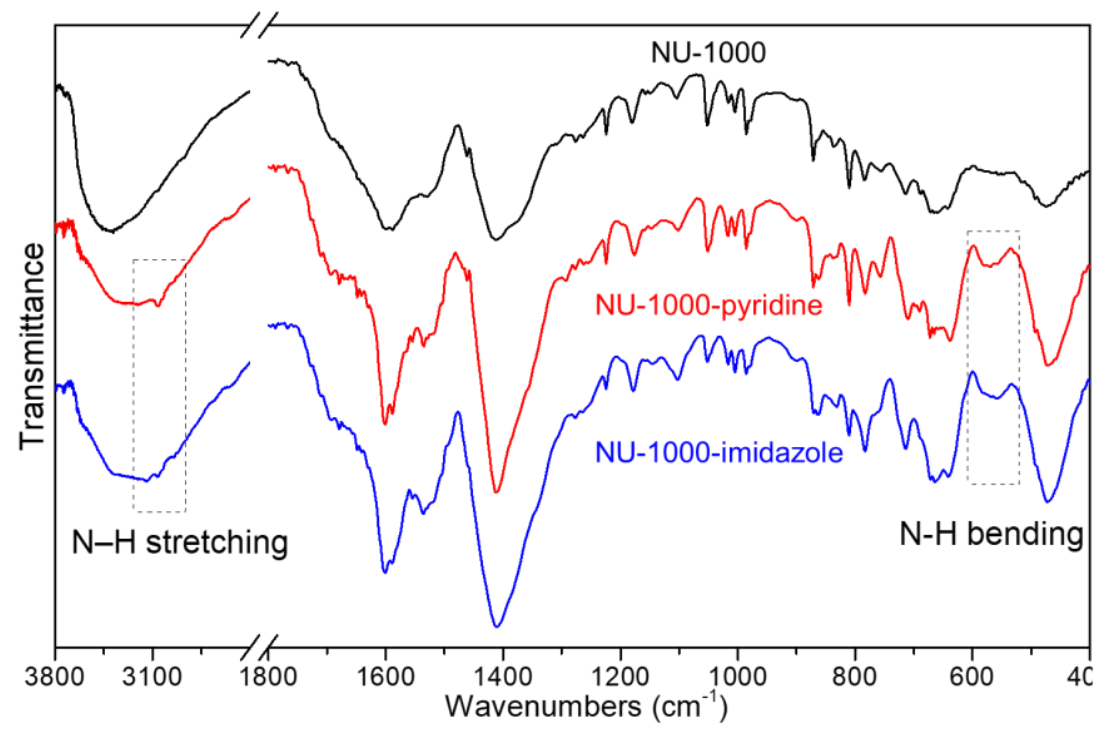

Figure S5. FTIR spectra of NU-1000, NU-1000-pyridine and NU-1000-imidazole.

Compared with the FTIR pattern of MOF-808, the new peaks of MOF-808-pyridine samples at about 1471, 1294, 1255, 1170, 1047, 1018, and $860 \mathrm{~cm}^{-1}$, are attributed to the presence of pyridine groups. The new peaks of MOF-808-imidazole samples at about 1489, 1260, 1163,1111, 997 and $800 \mathrm{~cm}^{-1}$, are attributed to the the presence of imidazole groups. Compared with the FTIR pattern of NU-1000, the new peaks of NU-1000-pyridine and NU-1000-imidazole samples at about 3100 and $550 \mathrm{~cm}^{-1}$, are attributed to the $\mathrm{N}-\mathrm{H}$ stretching on the nitrogen heterocyclic groups. ${ }^{1}$ 


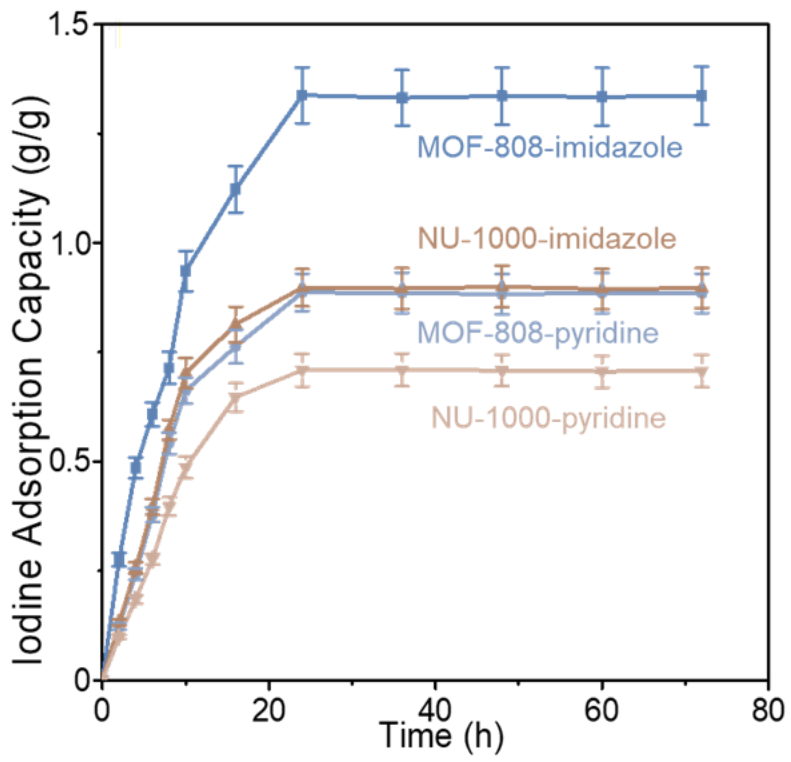

Figure S6. Adsorption curves for MOF-808/NU-1000-pyridine/imidazole at $80{ }^{\circ} \mathrm{C}$ in saturated iodine vapor.
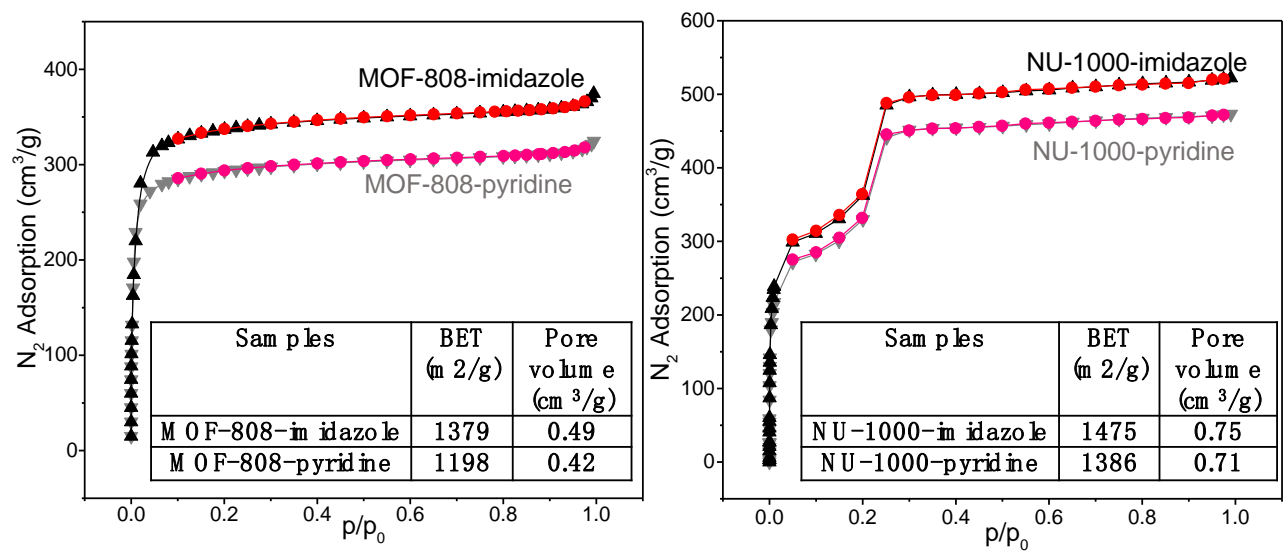

Figure S7. $\mathrm{N}_{2}$ adsorption-desorption isotherms and pore parameters of MOF808/NU-1000-pyridine/imidazole. 


\section{Pore parameters of $\mathrm{Zr}$-MOFs before and after iodine adsorption}

Table S1. Pore parameters of Zr-MOFs before and after iodine adsorption

\begin{tabular}{cccccc}
\hline Zr-MOFs & MOF-808 & NU-1000 & UiO-66 & MOF-867 & UiO-67 \\
\hline BET $\left(\mathrm{m}^{2} / \mathrm{g}\right)$ & 1930 & 2126 & 1072 & 2403 & 2638 \\
Pore volume $\left(\mathrm{cm}^{3} / \mathrm{g}\right)$ & 0.82 & 1.27 & 0.53 & 1.12 & 1.17 \\
$\mathrm{I}_{2}$ adsorption $(\mathrm{g} / \mathrm{g})$ & 2.18 & 1.45 & 0.66 & 0.88 & 0.53 \\
BET after $\mathrm{I}_{2}$ elution $\left(\mathrm{m}^{2} / \mathrm{g}\right)$ & 1304 & 856 & 735 & 457 & 309 \\
Pore volume after $\mathrm{I}_{2}$ elution $\left(\mathrm{cm}^{3} / \mathrm{g}\right)$ & 0.52 & 0.40 & 0.33 & 0.18 & 0.14 \\
Pore volume ratio & $63 \%$ & $31 \%$ & $62 \%$ & $16 \%$ & $12 \%$ \\
after $\mathrm{I}_{2}$ elution/before $\mathrm{I}_{2}$ adsorption & & & & & \\
\hline
\end{tabular}
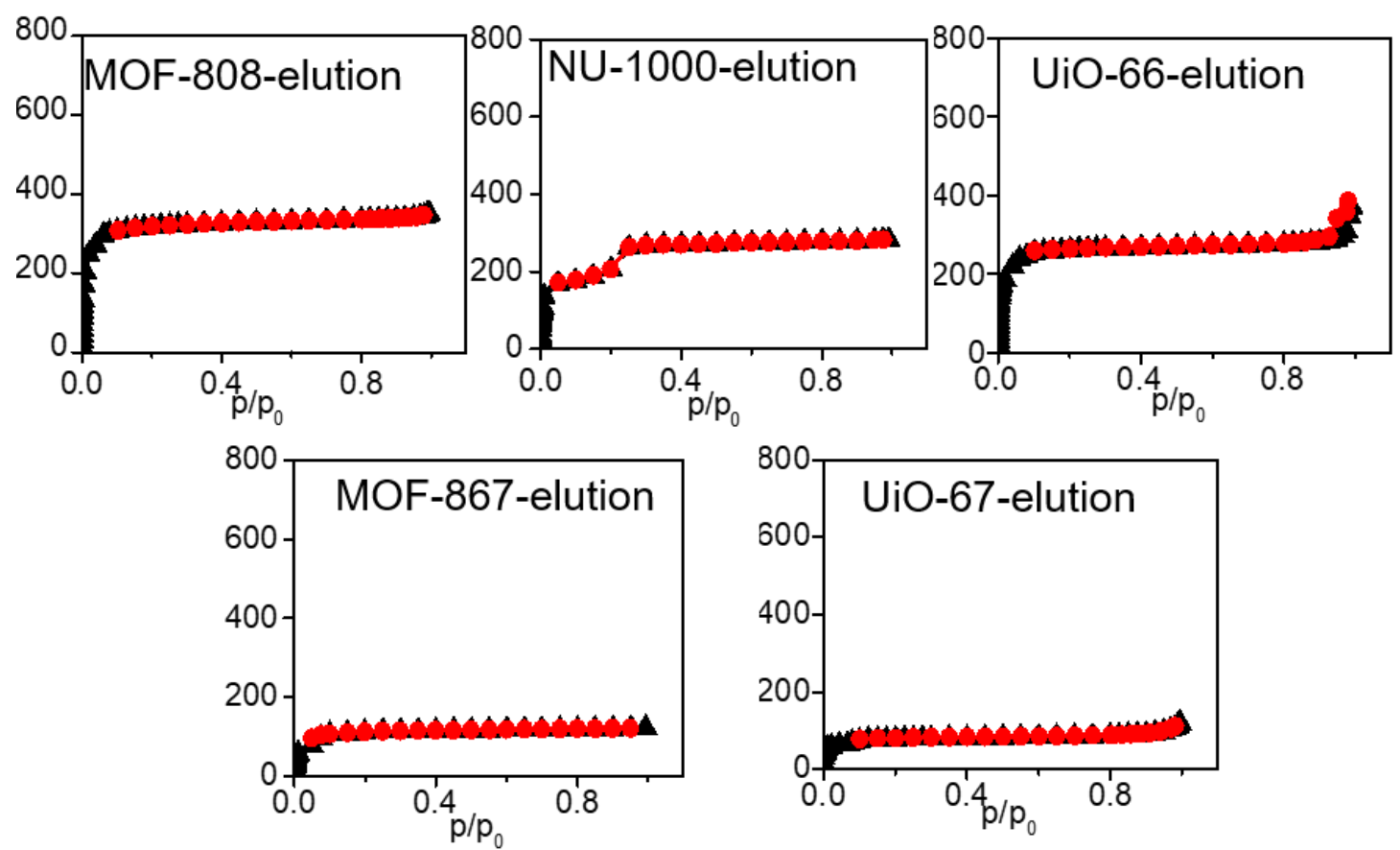

Figure S8. $\mathrm{N}_{2}$ adsorption-desorption isotherms of Zr-MOFs after iodine elution. 
5 PXRD of MOF-808-200\%iodine after elution by ethanol

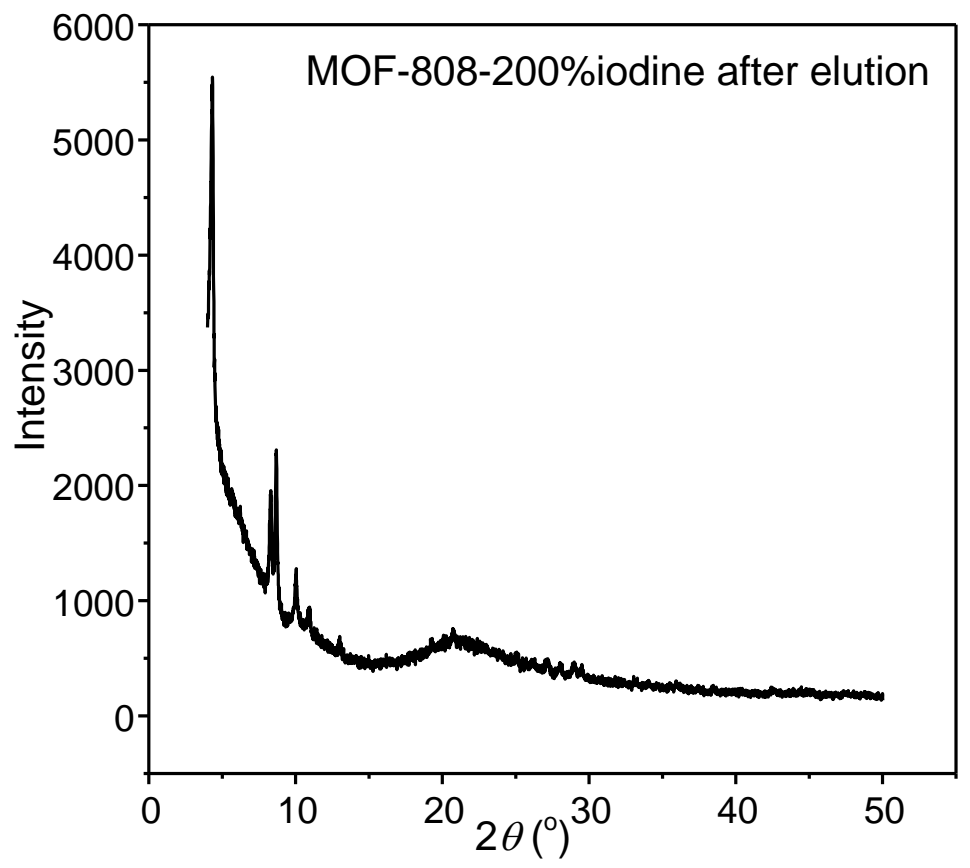

Figure S9. PXRD of MOF-808-200\%iodine after elution by ethanol.

\section{Structure refinements of MOF-808 and MOF-808-10\%iodine with PXRD data}

Flat plate diffraction data was collected for the range $2 \theta=4-50^{\circ}$ with a step size of $0.01^{\circ}$ and a scan rate of $2 \% \mathrm{~min}$. Profile fits were performed using the Le Bail method in the Fullprof program. ${ }^{2}$ where peaks shape was refined with pseudo-Voigt function. The background was modeled via 6-coefficients polynomial function and the origin of the polynomial is 40 . The models of the empty framework structure of MOF-808 were refined based on the previously published structures. ${ }^{3}$

Table S2. Unit cell parameters of MOF-808 and MOF-808-10\%iodine

\begin{tabular}{ccccc}
\hline Material & $\mathrm{a}(\AA)$ & $\mathrm{A}\left({ }^{\circ}\right)$ & $\mathrm{V}\left(\AA^{3}\right)$ & Space group \\
\hline MOF-808 & 35.278 & 90 & 43906 & $\mathrm{Fd} 3 \mathrm{~m}$ \\
MOF-808-10\%iodine & 35.253 & 90 & 43813 & $\mathrm{Fd} 3 \mathrm{~m}$ \\
\hline
\end{tabular}




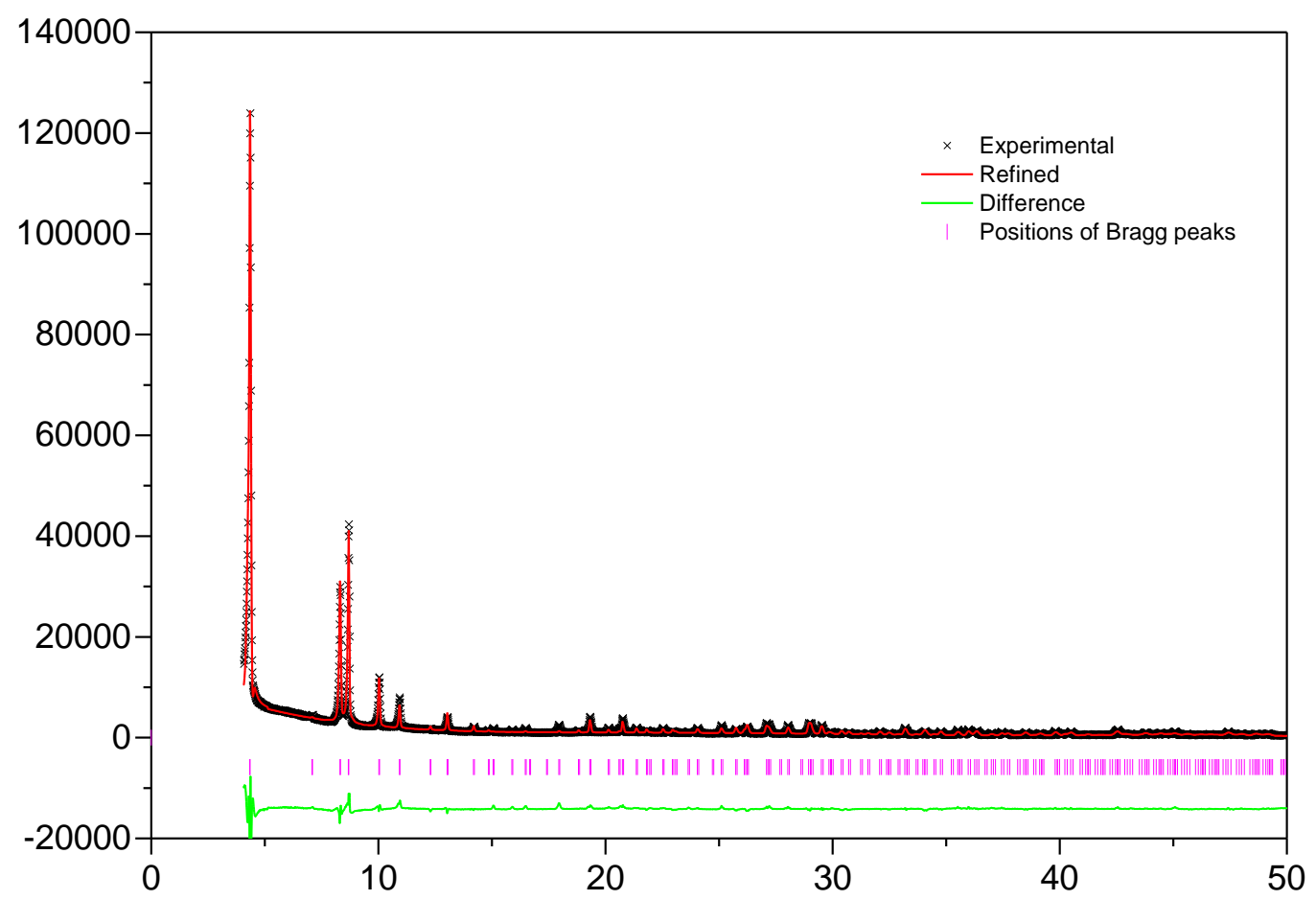

Figure S10. Le Bail refinement of MOF-808.

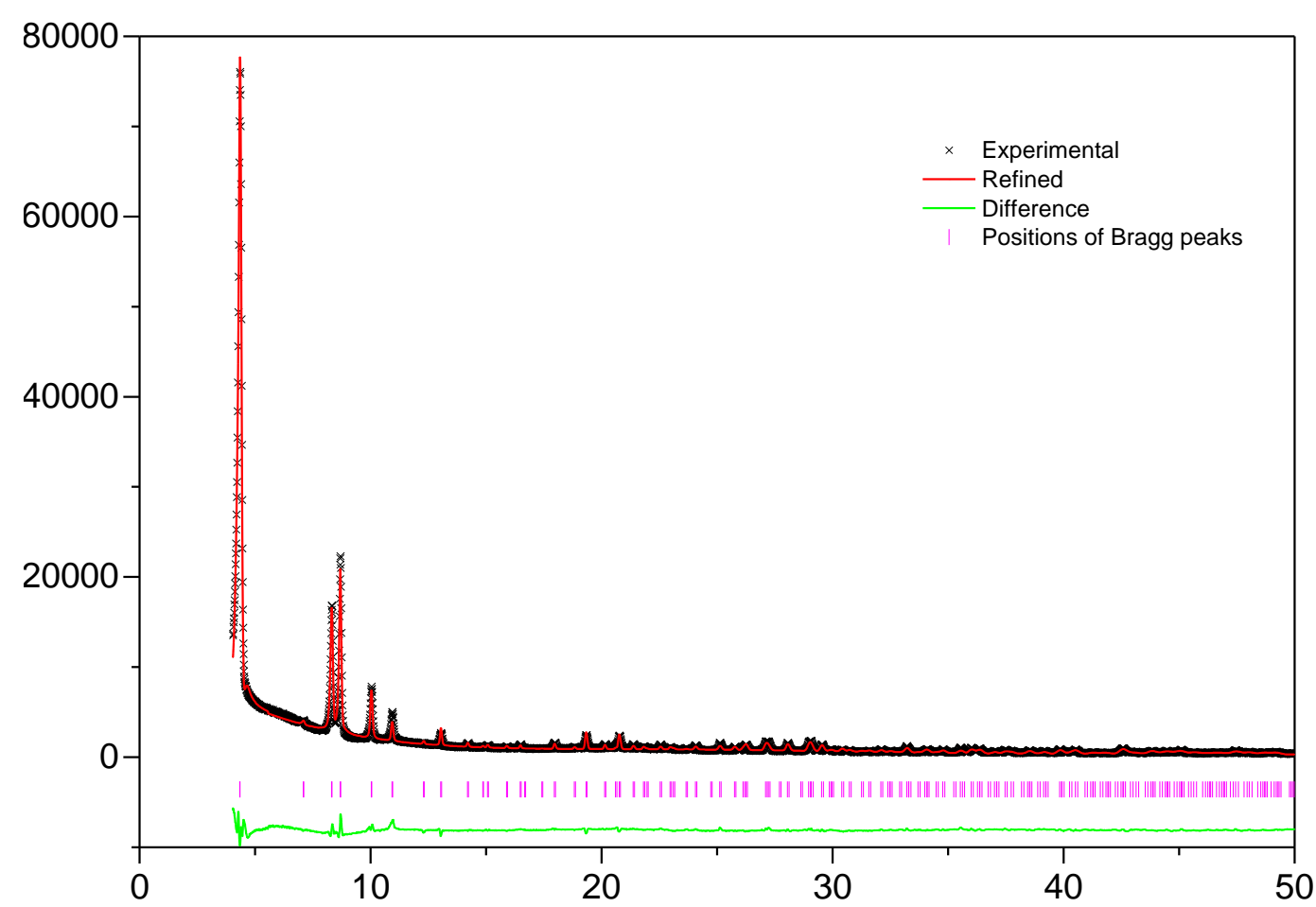

Figure S11. Le Bail refinement of MOF-808-10\%iodine. 
7 Raman of MOF-808 and MOF-808-10\%iodine

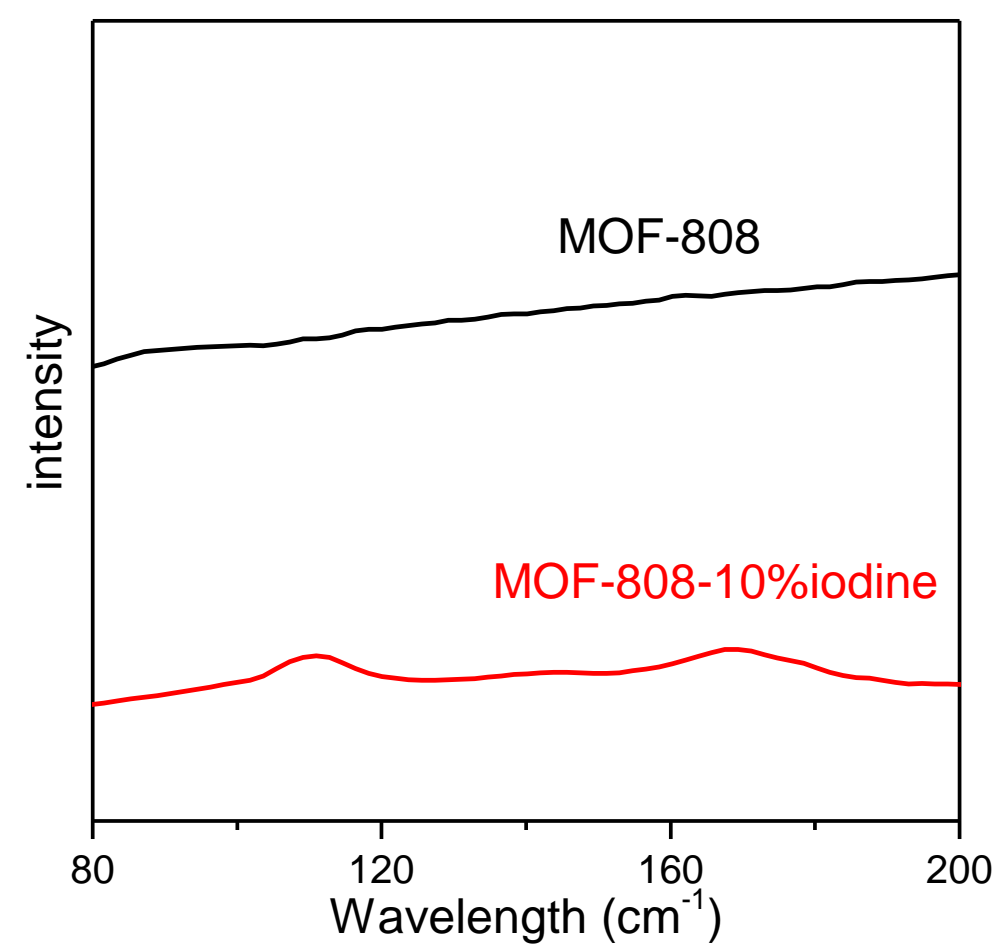

Figure S12. Raman of MOF-808 and MOF-808-10\%iodine

8 PXRD spectra of Zr-MOFs, iodine loaded Zr-MOFs and their products after elution by ethanol
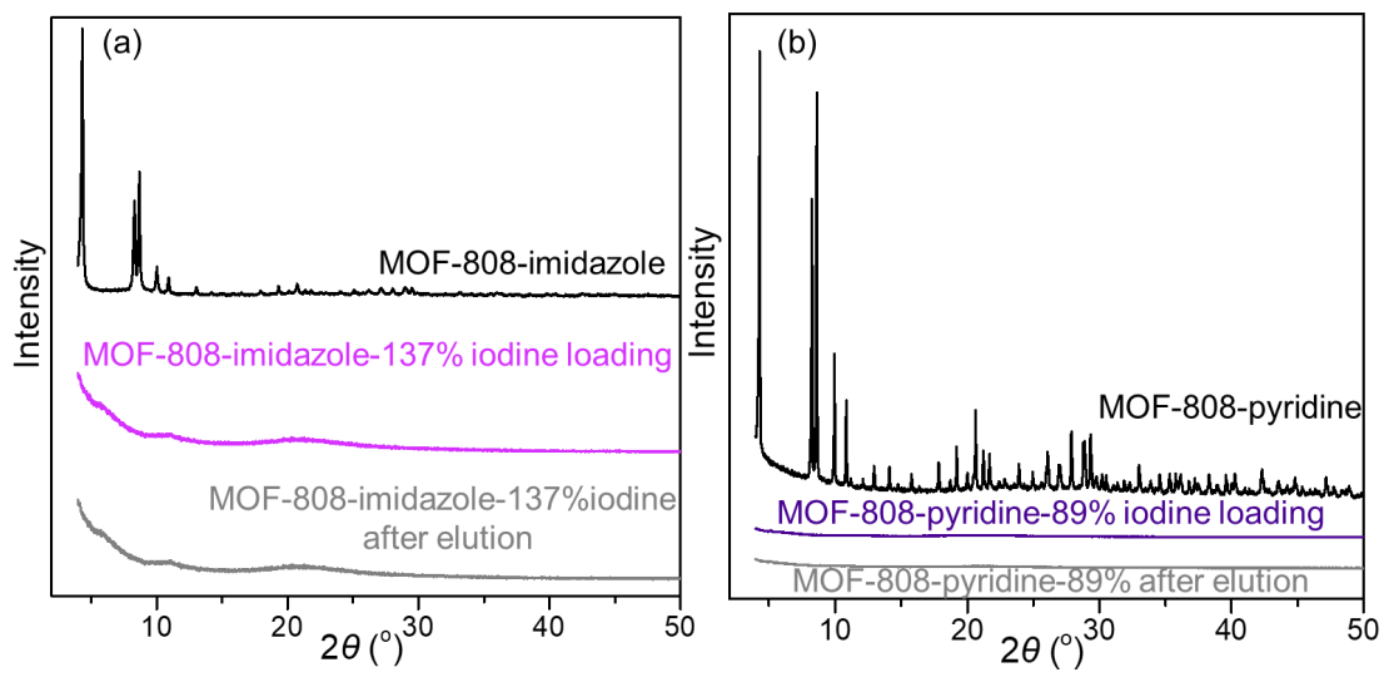

Figure S13. PXRD of MOF-808-imidazole/pyridine, iodine loaded MOF-808imidazole/pyridine and their products after elution by ethanol. 

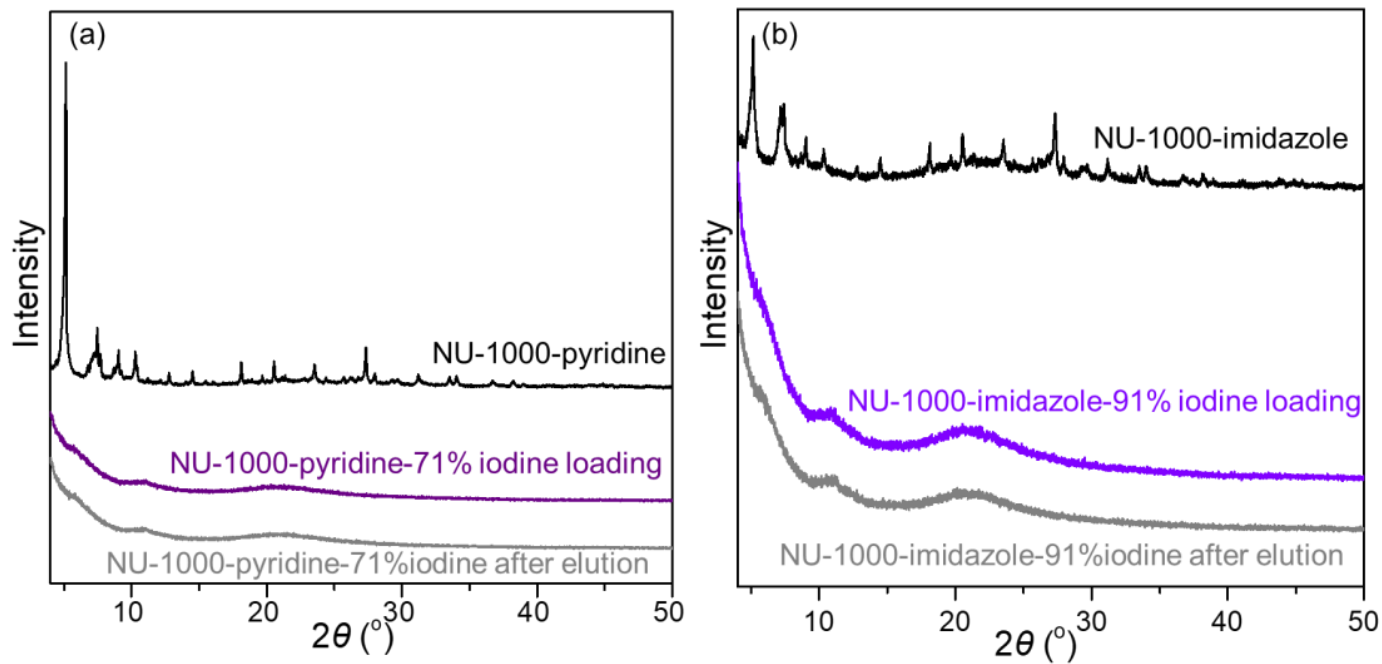

Figure S14. PXRD of NU-1000-imidazole/pyridine, iodine loaded NU-1000imidazole/pyridine and their products after elution by ethanol.

9 Raman of iodine loaded imidazole/pyridine incorporated MOF-808/NU-1000

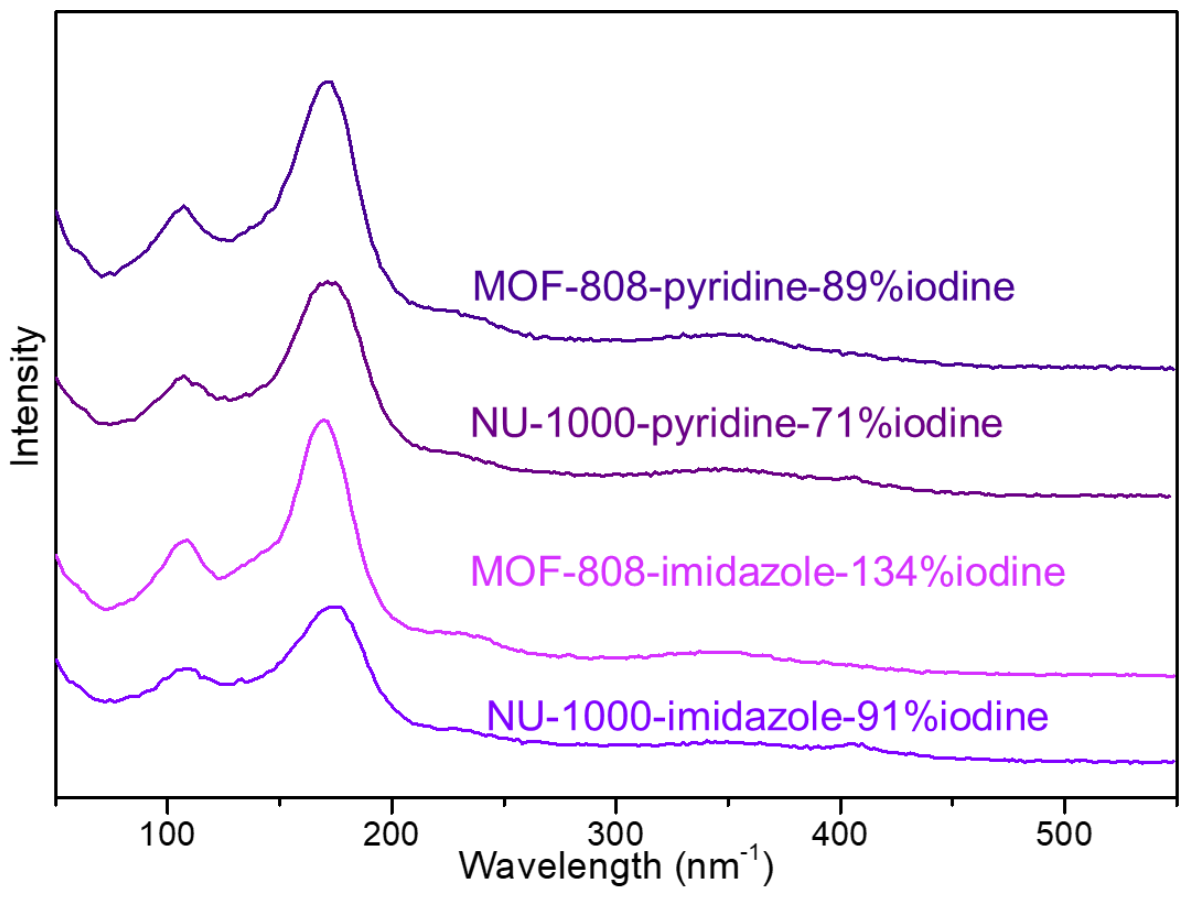

Figure S15. Raman of MOF-808/NU-1000-imidazole/pyridine. 
10 FTIR spectra of Zr-MOFs, iodine loaded Zr-MOFs and their products after elution by ethanol

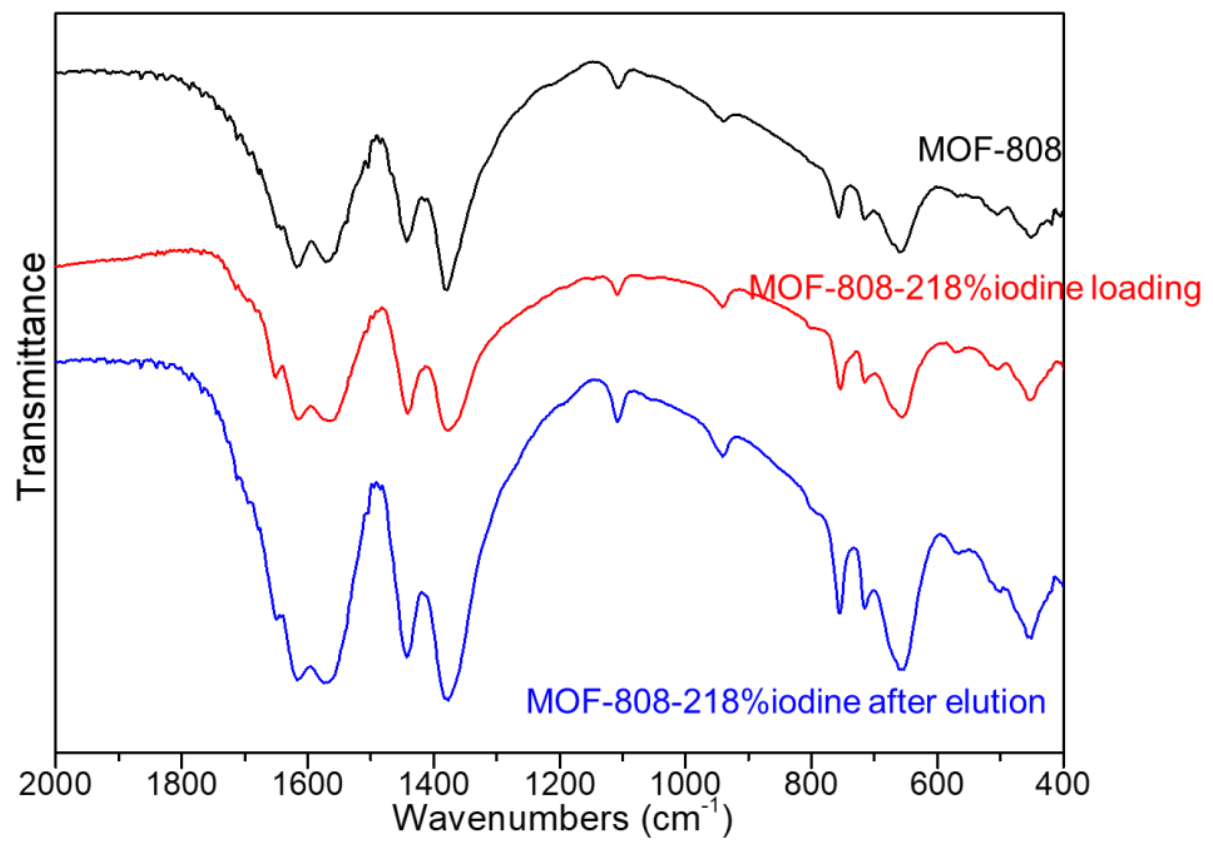

Figure S16. FTIR spectra of MOF-808, iodine loaded MOF-808 and its product after elution by ethanol.

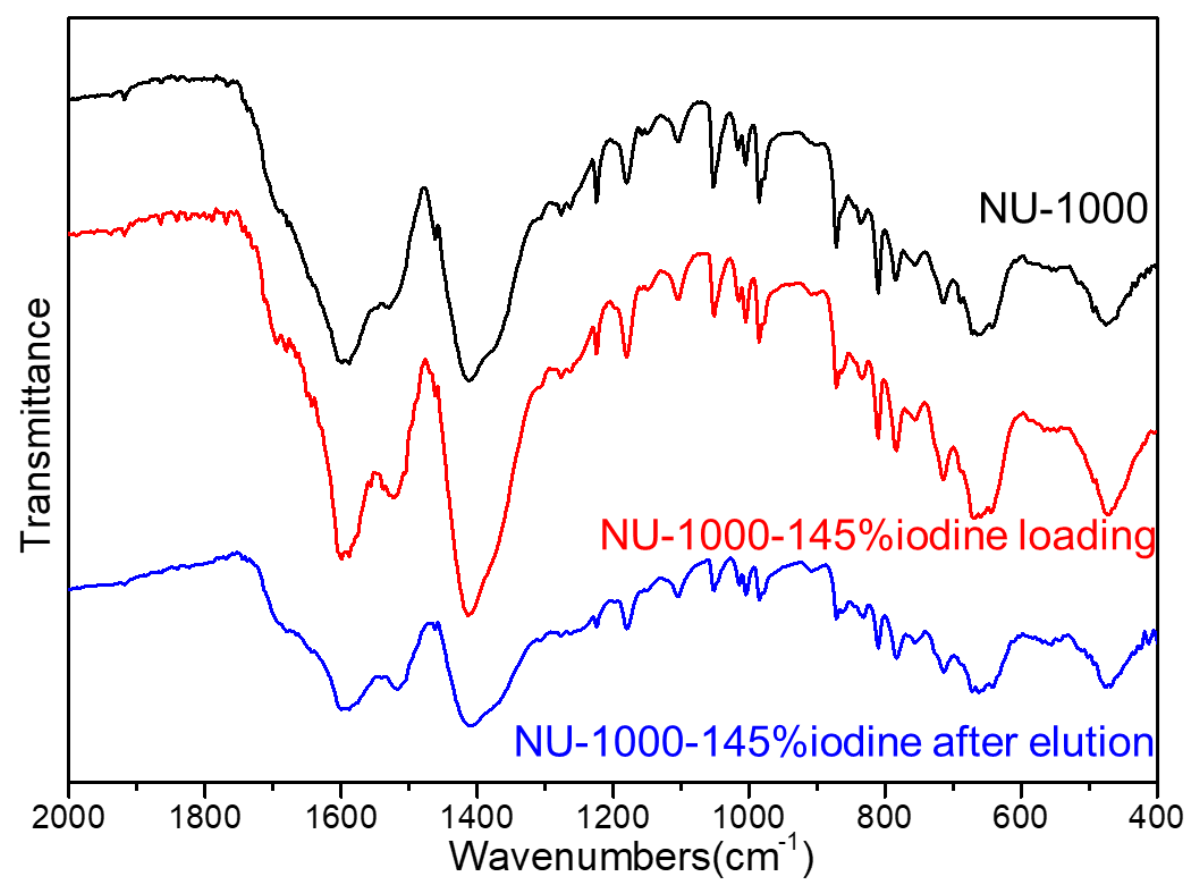

Figure S17. FTIR spectra of NU-1000, iodine loaded NU-1000 and its product after elution by ethanol. 


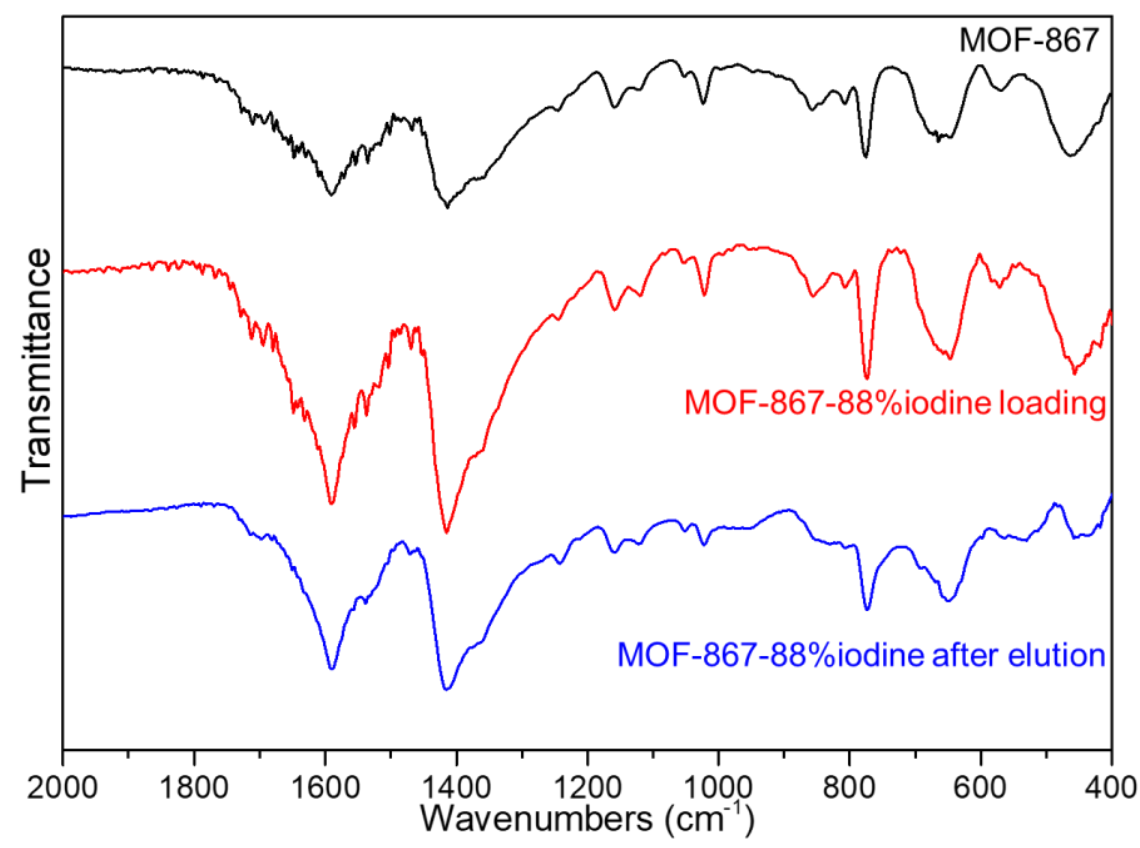

Figure S18. FTIR spectra of MOF-867, iodine loaded MOF-867 and its product after elution by ethanol.

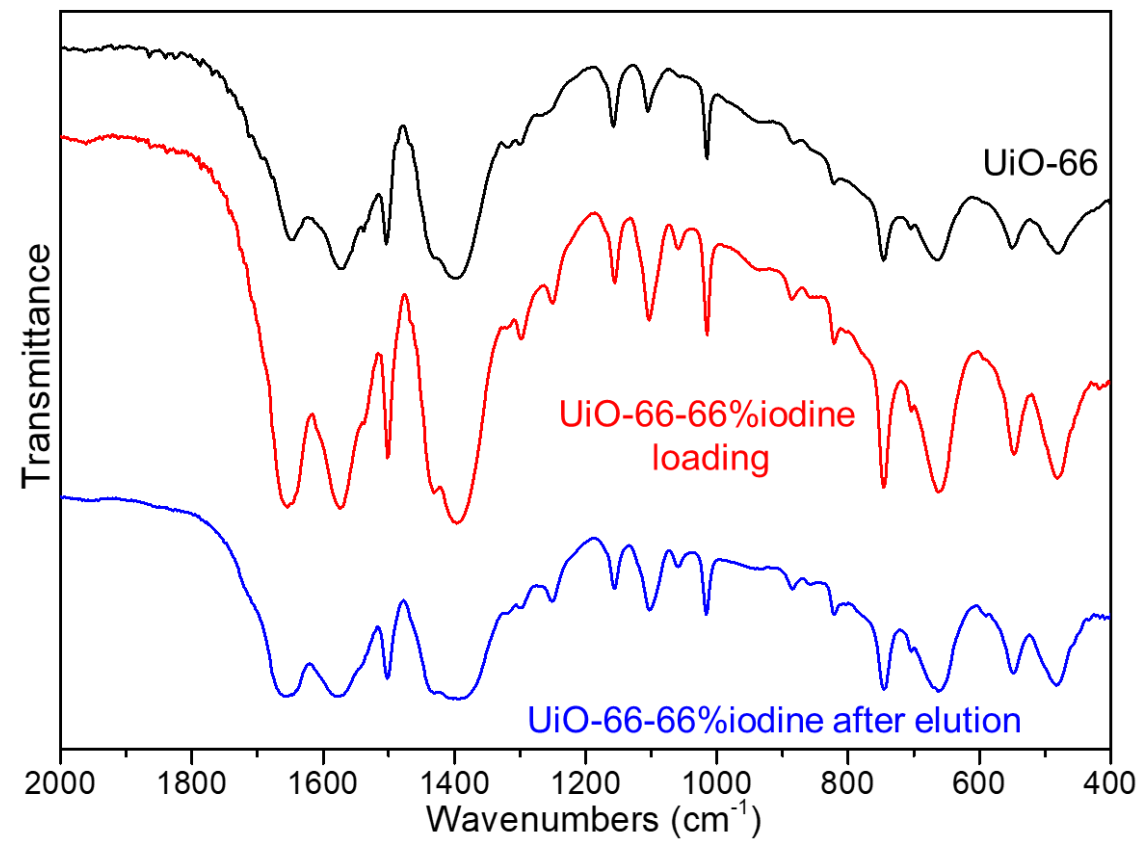

Figure S19. FTIR spectra of UiO-66, iodine loaded UiO-66 and its product after elution by ethanol. 


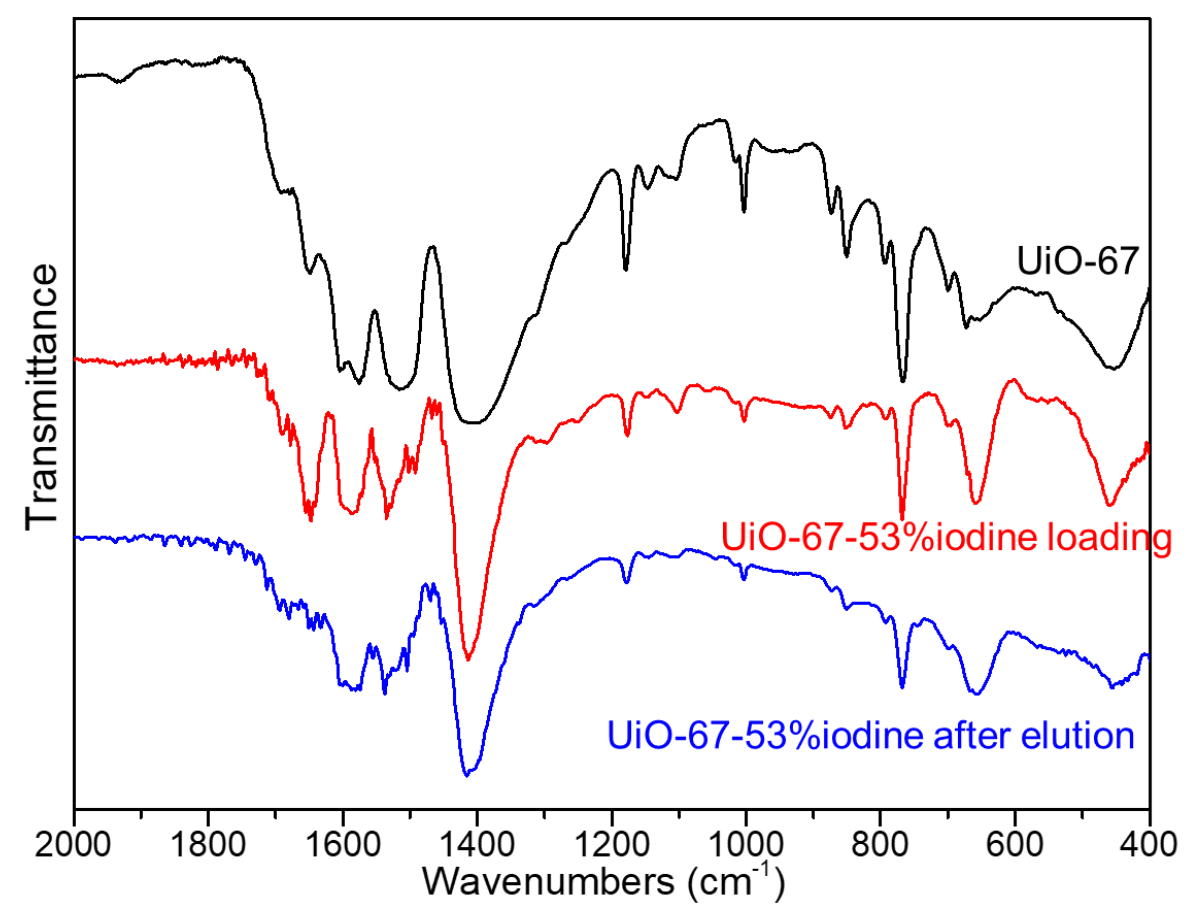

Figure S20. FTIR spectra of UiO-67, iodine loaded UiO-67 and its product after elution by ethanol.

11 Optimized geometries of the iodine molecule and $\mathrm{Zr}$ cluster of MOF-808

(a)

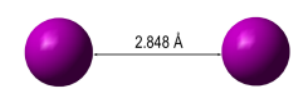

(b)

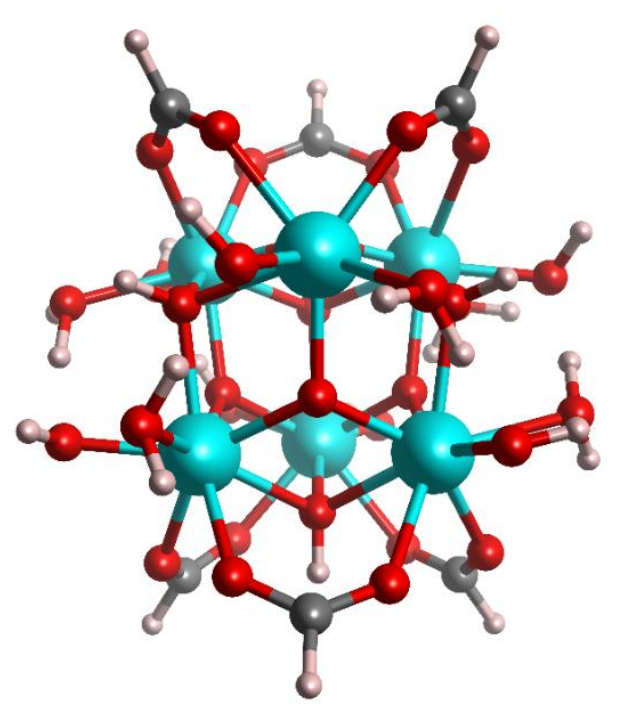

Figure S21. Optimized geometries of the (a) iodine molecule and (b) Zr cluster of MOF-808. 


\section{References}

1 Van Bael, M. K.; Smets, J.; Schoone, K.; Houben, L.; McCarthy, W.; Adamowicz, L.; Nowak, M. J.; Maes, G. Matrix-Isolation FTIR Studies and Theoretical Calculations of Hydrogen-Bonded Complexes of Imidazole. A Comparison between Experimental Results and Different Calculation Methods J. Phys. Chem. A 1997, 101, 2397- 2413

2 Rodríguez-Carvajal, J. Recent developments of the program FULLPROF. CPD Newslett. 2001, 26, 12; available at http://www.iucr.org/iucr-top/news/index.html. The program and documentation can be obtained from http://www.ill.eu/sites/fullprof/index.html.

3 Jiang, J.; Gándara, F.; Zhang, Y.-B.; Na, K.; Yaghi, O. M.; Klemperer, W. G., Superacidity in Sulfated Metal-Organic Framework-808. J. Am. Chem. Soc. 2014, 136, 12844-12847. 